\title{
Program Penggabungan Sekolah Dasar (SD) Dalam Meningkatkan Efektivitas dan Efisiensi Penyelenggaraan Pendidikan
}

\author{
Tita Setiawati ${ }^{1}$ \\ ${ }^{1}$ Universitas Pasundan
}

\begin{tabular}{l} 
ARTICLE INFO \\
\hline Article History: \\
Received 25.11.2017 \\
Received in revised \\
form 10.02.2018 \\
Accepted 26.03.2018 \\
Available online \\
12.04.2018
\end{tabular}

\begin{abstract}
The fact shows that the implementation of primary school level education must still receive attention, whether in the aspects of employment, finance, educational facilities and infrastructure which are still far from the desired expectations, the limited budget for education as well. The effort to improve the education budget appears to be in the current situation and condition, not yet possible to do. On the basis of that consideration, the policy of Primary School Regrouping is the most feasible effort to be done as a breakthrough step to realize efficiency and effectiveness in carrying out educational operational tasks. Judging from the public policy study the significance of the Elementary School regrouping program is to increase the success of effective and efficient primary school. While from the aspect of public interest, with the incorporation of Primary School can provide the best service to the public in the field of education. Further data obtained and the value of information that the policy of incorporation elementary school is appropriate to be implemented and has been able to create teaching and learning activities more effective and efficient. In addition, it has also been able to improve the work performance and motivation of principals and teachers in performing their duties, to improve the participation of the School Board significantly in assisting the smooth management of the school.
\end{abstract}

Keywords:

School Grouping, School Policy.
This is an open access article distributed under the terms of the Creative Commons Attribution 4.0 International License, which permits unrestricted use, distribution, and reproduction in any medium, provided the original work is properly cited. ( 2018 Tita Setiawati.

\section{PENDAHULUAN}

Sekolah Dasar merupakan jenjang pendidikan yang sangat mendasar sebagai fondasi membentuk sikap mental etika dan tatanan berfikir, sehingga akan membuka cakrawala wawasan anak didik dalam mengembangkan dirinya dimasa yang akan datang, atas dasar pemikiran itulah kebijakan penggabungan Sekolah Dasar sebagai upaya mengoptimalisasi sarana prasarana pendidikan dan penyempurnaan kelembagaan dalam rangka pengelolaan SD yang lebih efektif dan efisien merupakan kebijakan yang penting.

Kenyataan menunjukan bahwa penyelenggaraan pendidikan tingkat Sekolah Dasar masih harus mendapat perhatian, baik dalam aspek ketenagaan, keuangan, sarana dan prasarana pendidikan

${ }^{1}$ Corresponding author's address: Universitas Pasundan, Bandung, Indonesia

e-mail: tita.setiawati@unpas.ac.id 
yang masih jauh dari harapan yang diinginkan, terbatasnya anggaran pendidikan. Kondisi tersebut senantiasa jadi bahan pembicaraan dalam berbagai forum lembaga legislatif termasuk kalangan media masa, yang muncul senantiasa persoalan keterbatasan anggaran pendidikan. Sangat menarik pernyataan yang dikemukakan oleh Ginanjar Kartasasmita (1996: 283) bahwa hal yang penting dipertanyakan adalah apakah Bangsa Indonesia sudah melakukan sesuatu yang terbaik yang dapat dilakukan dalam keadaan serba terbatas ini.

Dengan keadaan seperti itu sudah tentu tidak harus menjadi alasan, untuk tidak berusaha meningkatkan pendidikan baik dari segi kualitas maupun kuantitas, tetapi bagaimana caranya agar penyelenggaraan pendidikan dapat berjalan secara efektif dan efisien dengan kondisi yang ada sekarang. Hal ini sejalan dengar pendapat H.A R. Tilaar (1998: 15) yang mengatakan bahwa, pengelolaan sistem pendidikan nasional apabila tidak dikelola dengan sebaik-baiknya maka bukan hanya tidak efektif tetapi juga tidak efisien. Dengan dana yang masih serba terbatas, peningkatan pengelolaan pendidikan nasional harus dilaksanakan. Salah satu upaya kearah itu adalah dengan mengoptimalisasikan sarana-prasarana pendidikan melalui regrouping Sekolah Dasar.

Sejak tahun 1973 pernerintah telah melaksanakan program pembangunan gedung-gedung Sekolah Dasar secara besar-besaran, dengan sasaran diarahkan untuk lebih terciptanya pemerataan dan keadilan dalam pedidikan, khususnya pada tingkat Pendidikan Dasar dalam rangka pelaksanaa Program Wajib Belajar.

Namun demikian, sebagai dampak dari pembangunan gedung Sekolah Dasar secara besar-besaran tersebut, memasuki awal Pelita VI terdapat banyaknya Sekolah Dasar yang mengalami kekurangan murid, disamping kondisi bangunan yang kurang terpelihara diakibatkan oleh keterbatasan dana pemeliharan. Hal ini terjadi sebagai dampak kelemahan kebijakan yang menganggap pembangunan gedung-gedung Sekolah Dasar secara besar-besaran sebagai terobosan dalam program wajib belajar 6 tahun, dengan tidak memperhitungkan kualitas bangunan serta proyeksi popu!asi siswa di masa yang akan datang. Kondisi seperti itu tentunya perlu dilakukan langkahlangkah penataan kembali kegiatan administrasi pendidikan. Ada dua hal yang dapat dilakukan yakni meialui peningkatan anggaran pendidikan atau dengan cara pemberdayaan sumber daya yang ada melalui langkah-langkah efisiensi.

Upaya untuk meningkatkan anggaran pendidikan tampaknya dalam situasi dan kondisi dewasa ini, dimana krisis ekonomi dan keuangan yang ternyata teiah berdampak pada segenap sendi-sendi perekonomian bangsa Indonesia belum mungkin untuk dilakukan.

Atas dasar pertimbangan itu, kebijakan regrouping Sekolah Dasar merupakan upaya yang paling memungkinkan untuk dilakukan sebagai langkah terobosan mewujudkan efisiensi dan efektivitas dalam menyelenggarakan tugas-tugas oprasional kependidikan.

Secara administratif Kota Sukabumi terbagi atas 7 kecamatan dan 33 Kelurahan, dilihat dari prespektif geografis beerada dalam lingkup wilayah Kabupaten Sukabumi. Luas wilayah kota Sukabumi sekitar $48 \mathrm{~km}^{2}$ (hanya 0,1 luas wilayah Jawa Barat), dihuni oleh sekitar 252.049 Peduduk ( $0.7 \%$ dari total Penduduk Jawa Barat). Jenis pendidikan formal yang ada terdiri dari Taman KanakKanak sebanyak 38, SD 173, SLTP 33, SMU 22 dan SMK 16 serta Perguruan Tinggi. Untuk dapat memberikan gambaran Iebih rinci disajikan pemetaan Sekolah Dasar yang merupakan kondisi awal dari rencana yang akan dilaksanakan penggabungan, seperti yang diuraikan dalam Gambar 1. 


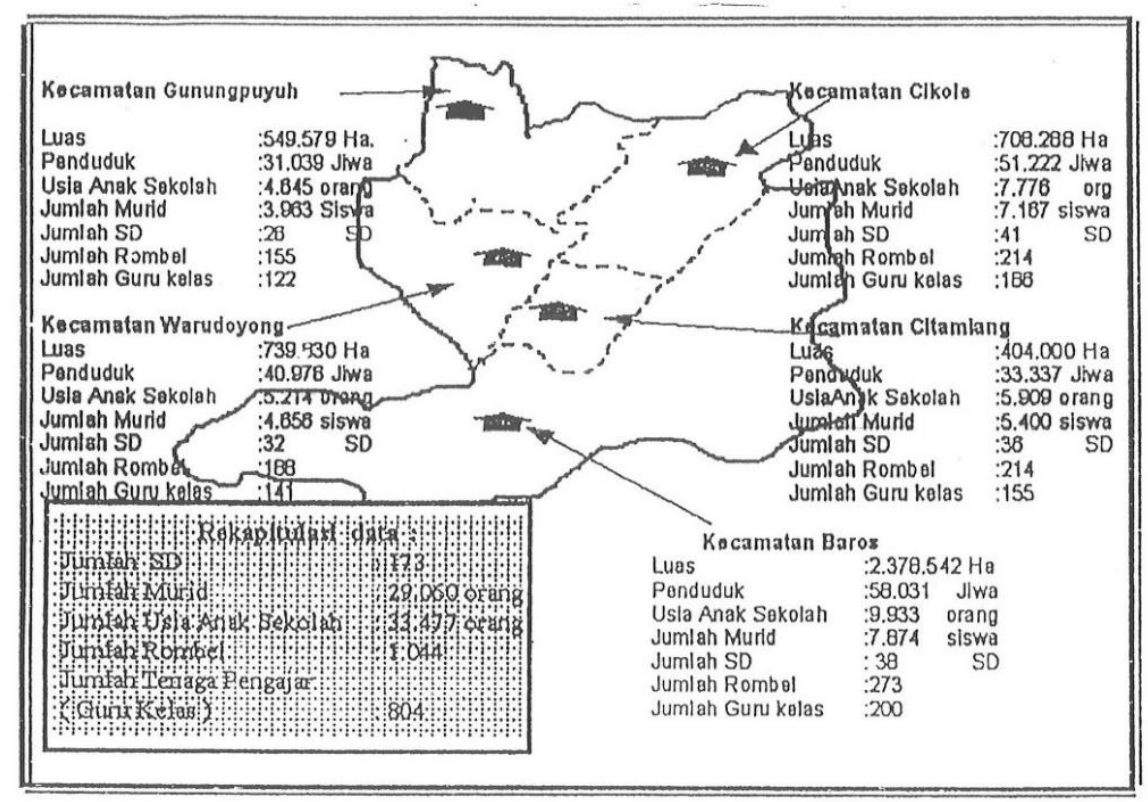

Sumber : Dinas P dan K Kota Sukabumi,

Gambar 1. Keadaan Sekolah Dasar Di Kota Sukabumi (Kondisi Awal)

Bertitik dari permasalahan yang melatar belakangi perlunya dilakukan program penggabungan (regrouping) SD, maka harapan yang ingin dicapai adalah terciptanya kondisi ideal didalam pengelolaan pendidikan dasar yang diuraikan dalam Gambar 2.

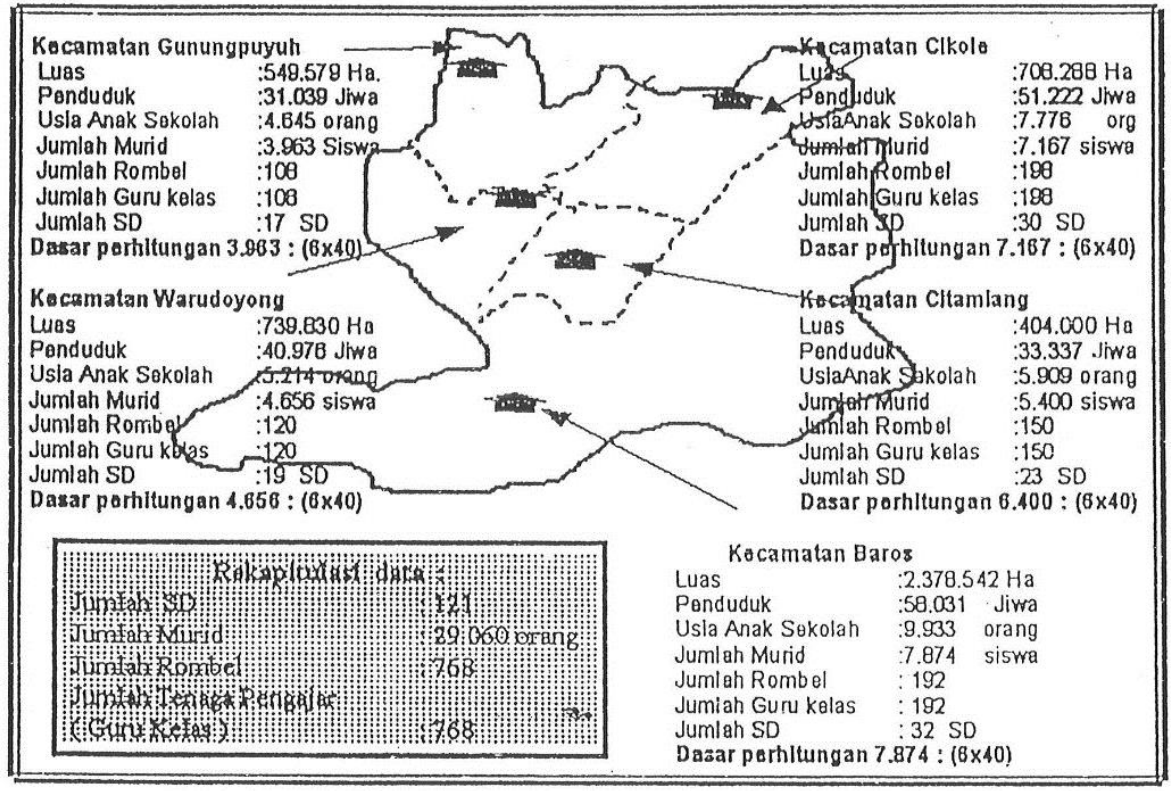

Sumber : Dinas P dan K Kota Sukabumi,

Gambar 2. Rasio Ideal Jumlah Sekolah Dasar Di Kota Sukabumi (Kondisi yang Diharapkan)

Dari keadaan Sekolah Dasar sebagai awal (Gambar 1) dibandingkan dengan kondisi yang diharapkan (Gambar 2) dengan merujuk kepada rasio ideal untuk satu rombongan belajar jumlah muridnya adalah 1: 40, (keputusan Dirjen Dikdasmen No.143/C/Kep/PP/1998, 6 Mei 1998), maka dengan demikian terdapat selisih sebanyak 52 SD yang perlu dilakukan penggabungan diakibatkan terjadinya kekurangan murid sebagai akibat dari penurunan usia anak sekolah 7-12 tahun dalam kurun waktu empat tahun terakhir. 
Berdasarkan kepada kendala yang dihadapi serta pentingnya upaya yang dilakukan dalam pernecahan masalah, maka sejauh mana kebijakan penggabungan (regrouping) sekolah Dasar dapat diimplementasikan dengan baik, sehingga berpengaruh terhadap meningkatnya efektivitas dan efisiensi penyelenggaraan pendidikan.

\section{METODE}

Dalam membahas analisis kebijakan tentang regrouping Sekolah Dasar, dalam rangka meningkatkan efektivitas dan efisiensi penyelenggaraan pendidikan dasar, diharapkan mendapat informasi tentang masalah yang dihadapi, fakta yang mendukung serta tindakan yang telah dan akan dilakukan dalam memecahkan masalah kebijakan penggabungan sekolah dasar. Untuk itu digunakan tiga macam pendekatan seperti yang dikemukakan oleh Dunn (2010).

1) Pendekatan empirik, dalam menganaiisis kebijakan regrouping Sekolah Dasar, pendekatannya terutama berkenaan dengan penggambaran sebab dan akibat dari kebijakan yang lalu, serta memberikan gambaran masa lalu tentang hasil yang diperoleh dari diberlakukannya kebijakan tersebut. Dalam pendekatan empirik pertanyaan utamanya ialah, apakah segala sesuatu itu ada dan jenis informasi yang dihasilkannya adalah berciri designative (mengindikasikan/menunjukan).

2) Pendekatan evaluatif, yaitu pendekatan yang berurusan dengan penentuan makna atau nilai dari kebijakan regrouping Sekolah Dasar di masa yang lalu. Pertanyaannya ialah apa makna dari kebijakan tersebut dan jenis informasi yang dihasilkannya bercirikan evaluatif.

3) Pendekatan normatif, yaitu pendekatan berkenaan dengan rekomendasi untuk masa yang akan datang, dari bentuk tindakan yang mungkin bisa memecahkan masalah yang berkaitan dengan kebijakan penggabungan Sekolah Dasar. Pertanyaannya adalah apa seyogyanya dilakukan, dan jenis informasi yang dihasilkan bersifat advokatif (mendukung, membantu). Pendekatan analisis kebijaksanaan seperti terlihat dalam Tabel 1.

Tabel 1. Pendekatan Analisis Kebijakan

\begin{tabular}{ccc}
\hline Approach & Primary question & Type Information \\
\hline Empirical (Fact) & Does it exist ? & Designatife \\
\hline Evaluative (Values) & of what orth is it - & Evaluative \\
\hline Normative (Action) & what should be done ? & Advocative \\
\hline & Sumber: Dunn (2010)
\end{tabular}

Untuk menghasilkan informasi yang relevan dengan kebijakan regrouping Sekolah Dasar, dilakukan pendekatan yang bersifat designatif, evaluatif, atau advokatif, dengan menggunakan prosedur analisis umum yaitu deskripsi, menurut Dunn (2010: 38) dijelaskan bahwa: "takes employing definite analytical procedures. As a process oe inquiry, policy analysis makes use general analitycal prosedur es that are common to all efforts to solve human problem Description, prediction, evaluation, and prescription".

Deskripsi dan prediksi yaitu membatu untuk menjawab pertanyaan yang bersifat designatif . Evaluasi membantu menjawab pertanyaan evaluatif seperti apa makna suatu kebijakan. Preskripsi membantu menjawab pertanyaan yang bersifat advokatif. Prediksi dan rekomendasi berhubungan dengan masa datang, digunakan sebelum suatu tindakan dilakukan (ex-ante), sedangkan deskripsi dan evaluasi bertahan dengan masa lalu digunakan sesudah sesuatu tindakan terjadi (ex-post).

Dalam menganalisis kebijakan regrouping Sekolah Dasar, prosedur analisis umum yang berkaitan dengan metode analisis kebijakan yaitu:

1) Pemantauan (monitoring), yang memungkinkan menghasilkan informasi mengenai sebab akibat dari kebijakan masa lalu,

2) Prakiraan (forecasting), yaitu meprediksi yang memungkinkan menghasilkan informasi mengenai konsekuensi di masa datang dari berbagai kebijakan.

3) Evaluasi (evaluation), yaitu melibatkan hasil informasi mengenai makna kebijakan masa lalu dan masa depan. 
4) Rekomendasi (recommendation), yaitu menyajikan preskripsi yang memungkinkan cara bertindak di masa depan yang akan membawa akibat yang bernilai. Sebagai tambahan dari keempat metode analisis kebijakan tersebut adalah Problem structuring, yaitu tahapan dalarn proses penelaahan permasalahan (penstrukturan masalah), Practical inference, penyimpulan secara praktis, sejauh mana masalah l:ebiiakan sudah dapat dipecahkan.

\section{HASIL DAN PEMBAHASAN}

Masalah yang dihadapi sering kali tidak dapat diidentifikasi dengan benar, sehingga mengakibatkan implementasi suatu kebijakan menemui kegagalan. Dalam upaya menghindari hal tersebut, maka untuk merumuskan suatu kebijakan memerlukan analisis kebijakan yang dibahas oleh beberapa ahli Untara lain, William N. Dunn (2010: 35) memberikan definisi tentang analisis kebijakan sebagai berikut: "Policy analysis an applied social science discipline which uses multiple meth odes of inquiry and argument to produce and transform policy relevant information that may be utized in political setting to resolve policy problem".

Dalam arti luas, analisis kebijakan adalah suatu bentuk riset terapan yang dilakukan untuk memperoleh pengertian tentang masalah-masalah sosioteknis untuk merighasilkan pemecahanpemecahan yang lebih baik (Moekijat, 2010: 5). Merujuk pengetian tersebut diatas, maka analisis kebijakan bertujuan untuk membantu para pengambil kebijakan publik memecahkan masalahmasalah yang mereka hadapi.

Moekijat selanjutnya mengemukakan istilah "analisis kebijakan" diterapkan baik terhadap proses (atau kegiatan) maupun hasil dari kegiatan, dengan demikian analisis kebijaksanaan akan menghasilkan banyak analisis kebijaksanaan. Dari beberapa pengertian anailis kebijakan tersebut diatas dengan mengikuti pengertian bahwa anailis kebijakan dilakukan untuk membantu para pengambil kebijakan dalam memecahakan masalah dan dapat diterapkan pada semua tahapan kebijakan dimulai dari proses penyusunan kebijakan, implementasi dan

Penilaian hasil dari kebijakan. Tjokroamidjojo dan Mustopadidjaya (2009: 99) mengemukakan dua hal yang esensial dalam analisis kebijakan yaitu: pertama, penelitian untuk mendapatkan data dan informasi bertalian dengan persoalan yang dihadapi. Kedua, mencari dan mengkaji berbagai alternatif pemecahan persoalan atau pencapaian tujiaan, keduanya itu dilakukan secara multi disipliner. Lahirnya suatu kebijakan dapat dilihat dari prosesnya. Thomas R Dye (1992) mengemukakan tentang proses suatu kebijakan (policy). The result is a set of policy prosesses which usually follow this gentral outline.

Penggabungan (regrouping) Sekolah Dasar sebagai upaya untuk melakukan penataan kembali pengelolaan pendidikan dasar di tingkat Sekolah Dasar yang akan berpengaruh pula terhadap kegiatan administrasi pendidikan.

Pendidikan itu sendiri pada dasarnya merupakan suatu sistem, yakni sepe: angkat obyek yang memiliki sejumlah kornponen yang saling berhubungan satu sama lain. Seperti yang dikemukakan oleh Nana Sudjana (2010: 23), bahwa: "Sistem dapat dipandang sebagai suatu bentuk dalam struktur atau operasi, konsep atau fungsi, yang terjalin dari bagiaan yang terikat dan terpadu". Hakikat sistem selalu ditandai adanya masukan (input)-proses-dan keluaran (output), berdasarkan fakta, kendala serta faktor-faktor yang mempengaruhinya, maka dapatlah dirumuskan kerangka pemikiran sebagai alur pikir kebijakan regrouping Sekolah Dasar seperti dalam gambar 1.3. Alur pikir tersebut, dipandang dari sudut analisis "Input-Output", Input yang memasukan sesuatu sistem dapat berupa: zat energi, manusia atau informasi. la merupakan kekuatan yang menggerakan, yang memberikan kepada sistem yang bersangkutan, apa dipalukan untuk dapat beroperasi (Nisjar \& Winardi, 1997), dari uraian yang dikemukakan di atas, dapat diasumsikan seperti pada Gambar 3. 


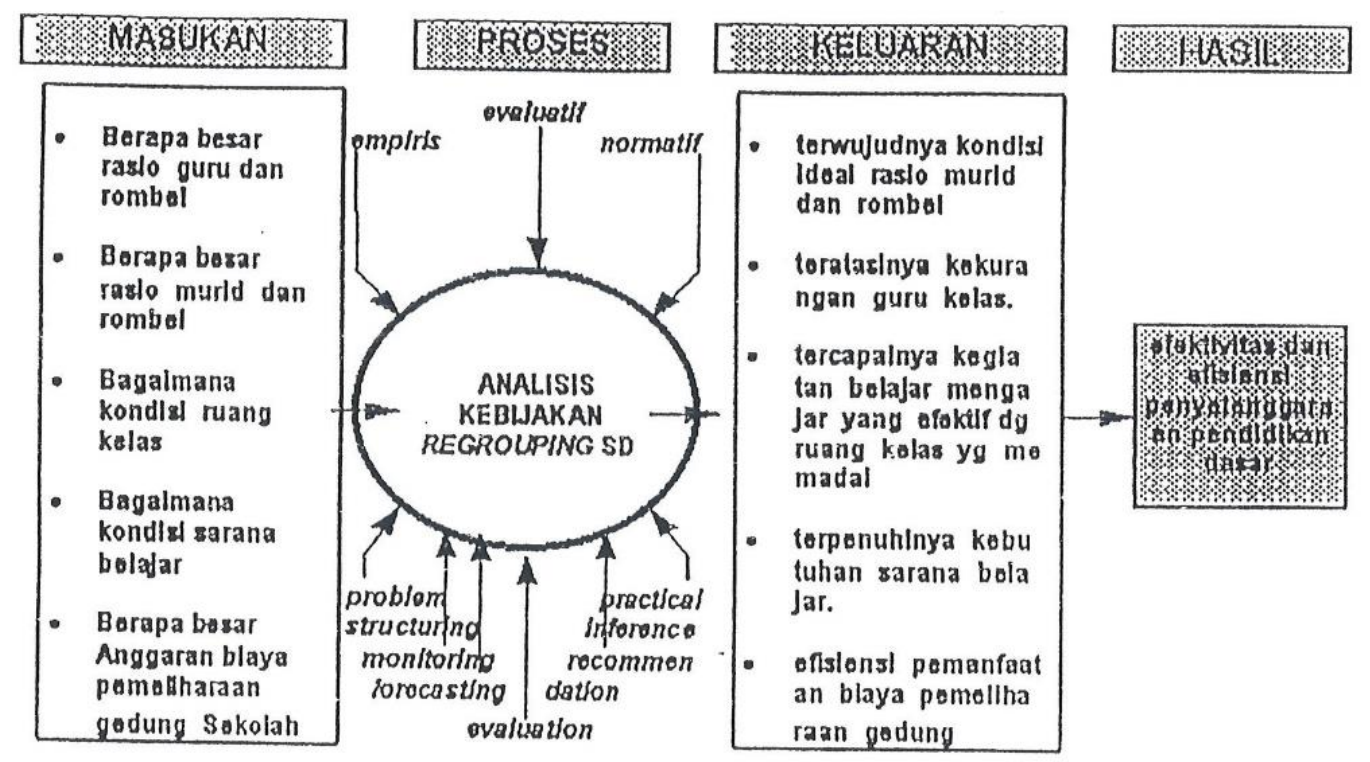

Gambar 3. Alur Pikir Analisis Kebijakan Penggabungan Sekolah Dasar

1) Input, yaitu menganalisis latar belakang masalah yang menyebabkan perlunya dilakukan regrouping Sekolah Dasar.

2) Proccess, menganalisis kebijakan regrouping Sekolah Dasar dengan menggunakan pendekatan empiris, evaluatif, dan normatif, serta monitoring, forecasting, evaluation, recommendation, problem structuring, dan practical inference.

3) Output, melalui proses analisis kebijakan regrouping Sekolah Dasar diharapkan tercapainya rasio ideal dalam penyelenggaraan pendidikan.

4) Outcomes, tercapainya hasil yang diharapkan dalam penyelenggaraan pendidikan dasar yang efektif dan efisien.

Berdasarkan data dan informasi yang dapat dihimpun, dapat meyakinkan kepastian akan pentingnya penggabungan sekolah yang kurang efektif. Dengan upaya penggabungan sekolah tersebut, diperoleh beberapa strategi pelaksanaan penggabungan dengan mempehatikan konsep perencanaan yang matang. Informasi yang dhimpun dapat dirinci langkah-langkah strategis sebagai berikut:

Dalam proses perencanaan penggabungan hendaknya ada beberapa unsur yang harus dilibatkan:

1) ajaran personil pada sistem persekolahan, yaitu: Kepala Sekolah, guru, siswa, pembantu sekolah;

2) Dewan Sekolah dan orang tua siswa; 3) Dinas Instansi terkait.

Ada beberapa faktor penunjang yang harus menjadi perhatian dalam tahap perencanaan, yaitu:

1) Pemilihan lokas untuk penggabungan sekolah, tidak semata-mata atas alasan dekat, akan tetapi harus mempertimbangkan kepentingankepentingan edukatif, seperti pemilihan sekolah yang letaknya strategis yaitu sekolah yang memiliki tingkat resiko rendah, lingkungan yang nyaman tidak dekat pasar, terminal atau keramaian lain yang dapat mengganggu proses pembelajaran.

2) Bangunan sekolah yang dipilih untuk menerima pengabungan harus memenuhi persyaratan fisik bangunan yang baik dengan ruang belajar yang memadai.

3) Berpotensi untuk sekolah yang bermutu, yaitu sekolah yang dipilih sebagai sekolah penerima pengabungan adalah sekolah yang harus memiliki potensi-potensi lebih dibading sekolah lainnya. Kelebihan-kelebihan potensi itu baik secara kualitatif maupun secara kuantitatif dalam bidang ketenagaan, siswa, kelengkapan sarana dan prasarana, program kurikuler yang terprogram dengan baik.

Rencana penggabungan sekolah baik dalam satu kompleks ataupun bagi sekolah yang tidak dalam satu kompleks, tetapi letaknya berdekatan diharapkan dengan penggabungan akan tercipta suatu 
proses belajar mengajar dengan baik. Dari hasil observasi dan wawancara telah dapat diterima bahwa dengan penggabungan Sekolah Dasar ternyata dapat berpengaruh terhadap efektivitas proses belajar mengajar. tolak ukur dari pengaruh tersebut antara lain .

1) Terpenuhinya kebutuhan tenaga pengajar, sehingga terdapat keseimbangan antara rasio guru dengan rombongan belajar.

2) Terdapatnya rasio murid dengan rombongan beiajar mendekati raslo ideal sehingga secara bertahap tercipta proses belajar yang lebih efektif.

3) Target pencapaian kurikulum dapat terpenuhi, aktifitas ekstra kurikuler dapat berlangsung dengan baik sehingga telah dapat meningkatkan kamampuan hasil belajar.

4) Supervisi dan monitoring terhadap kegiatan belajar mengajar dapat berlangsung secara baik oleh karena itu rentang kendali pengawasan, yang semakin pendek.

5) Tercapainya produktivitas pembelajaran yang lebih baik dibuktikan dengan nilai rapor dan nilai ujian sekolah/nasional siswa yang semakin menunjukan peningkatan.

Dampak lain dari kebijakan penggabungan Sekolah Dasar adalah terwujudnya pengelolaan sekolah yang lebih efisien, pemborosan dapat dihindari dan pemanfaatan sumber-sumber dana tenaga waktu dapat dimanfaatkan sebaik-baiknya, sehingga melalui kebijakan penggabungan kegairahan dan motivasi kerja tenaga pegajar meningkat, semangat belajar siswa membaik hal ini dibuktikan dengan observasi langsung ke Sekolah Dasar Dewi Sartika I sebagai SD yang menerima penggabungan dari 5 Sekolah Dasar. Selain itu hasil observasi dan dokumentasi menunjukan prosentase kehadiran guru semakin membaik berkisar rata -rata $0.4 \%$ yang tidak hadir setiap bulan, sedangkan siswa tingkat kehadirannya rata-rata perbulan $95 \%$.

Dari uraian di atas maka dapat disimpulkan bahwa melalui penggabungan Sekolah Dasar ternyata sangat berpengaruh tidak saja menghemat anggaran biaya operasional pendidikan-, namun lebih jauh secara bertahap dapat mwujudkan kondisi ideal antara rasio murid dan rombongan belajar, begitu pula kebutuhan guru secara berangsur-angsur akan terpenuhi.

\section{SIMPULAN}

Program penggabungan Sekolah Dasar adalah meningkatkan keberhasilan penyelenggaran Sekolah Dasar yang efektif dan efisien, sedangkan dari aspek kepentingan publik, dengan penggabungan Sekolah Dasar dapat memberikan pelayanan yang terbaik kepada masyarakat di bidang pendidikan. Selanjutnya diperoleh data dan nifai informasi bahwa kebijaksanaan penggabungan Sekolah dasar sudah tepat untuk dilaksanakan dan telah mampu menciptakan kegiatan belajar mengajar yang lebih efektif dan efisien disamping itu telah mampu pula meningkatkan kinerja dan motivasi kerja para Kepala Sekolah dan guru dalam melaksanakan tugasnya, meningkatnya partisipasi Dewan Sekolah secara signifikan dalam membantu kelancaran pengelolaan sekolah.

Kebijakan penggabungan (regrouping) Sekolah Dasar dapat dilaksanakan, jika formasi jabatan Kepaia Sekolah Dasar tersedia. Sedangkan faktor lainnya yang perlu mendapat perhatian adalah sosialisasi program pennggabungan Sekolah Dasar lebih ditingkatkan sampai kepada masyarakat/ orang tua murid.

Program penggabungan sekolah Dasar sebagai suatu konsep dan strategi manajemen pendidikan dasar telah mampu mewujudkan pengelolaan Pendidikan Dasar yang lebih efektif dan efisien. Agar kebijakan penggabungan Sekolah Dasar dapat diimplemetasikan dengan baik dan tidak menimbulkan ekses negatif pelaksanaannya dilakukan secara bertahap.

Dalam melaksanakan penggabungan Sekolah Dasar, faktor-faktor yang perlu mendapat perhatian adalahpotensi sekolah yang menerima penggabungan harus memperhatikan aspek teknis kependidikan dan aspek teknis bangunan dan lingkungan sekolah yang mendukung berlangsungnya kegiatan belajar mengajar yang baik. 


\section{REFERENSI}

Badudu, J. S., \& Sutan, M. Z. (2004). Kamus Umum Bahasa Indonesia. Jakarta: Pustaka Sinar Harapan.

Dunn, W. N. (2010). An Introduction Public Policy Analysis. Engle wood diffs, NJ: Printice-Hall.

Dye, T. R. (1992). Understanding public policy. Englewood Cliffs, NJ: Prentice Hall.

Fattah, N. (2006). Landasan Manajemen Pendidikan. Bandung: Remaja Rosda Karya.

Hitt, M. A. R., Ireland, D., \& Hoskisson, R. E. (2007). Strategic Management: Competitiveness and Globalization. Cincinnati, Ohio: South-Western.

Islamy, M. I. (2007). Prinsip-prinsip Perumusan Kebijaksanaan Negara. Jakarta: Bina Aksara.

Kartasasmita, G. (1996). Pembangunan untuk rakyat: memadukan pertumbuhan dan pemerataan. Jakarta: Cides.

Keputusan Gubernur KDH Tingkat I Jawa Barat. Tanggal 6 Februari 1999 tentang Petunjuk Pelaksanaan Penggabungan Sekolah Dasar di Propinsi Jawa Barat.

Moekijat. (2010). Manajemen Sumber Daya Manusia. Bandung: Mandar Maju.

Nisjar, K., \& Winardi. (1997). Manajemen Strategik, cet. I. Bandung: Mandar Maju.

Surat Direktorat Jendral Pembangunan Daerah Departemen Dalam Negeri Nomor 421.2/1631/II/Bangda. Tanggal 16 Juli 1999. Perihal Penyesuaian/ Penyempurnaan Pedoman Pelaksanaan Penggabungan (regrouping) SD.

Surat Gubernur KDH Tingkat I Jawa Barat no. 421.2I1690/Dis.PK. Tanggal 31 Mei 1996. Perihal Penggabungan (regrouping) SD yang kurang efektif.

Surat Menteri Dalam Negeri Republik Indonesia No. 421.2/2501/Bangda. Tanggal 16 Nopember 1998. Perihal pelaksanaan Penggabungan (regrouing) SD.

Suryadi, A., \& Tilaar, H. A. R. (2003). Analisis Kebijakan Pendidikan suatu Pengantar. Bandung: Remaja Rosdakarya.

Sudjana, N. (2005). Penilaian hasil Proses Belajar mengajar. Bandung: Remaja Rosdakarya.

Sutisna, O. (2009). Administrasi Pendidikan: Dasar Teori untuk praktek Profesional. Bandung: Angkasa.

Tjokroamidjojo, H. B., \& Mustopadidjaya, A. R. (1996), Teori dan Strategi Pembangunan Nasioal, Cetakan Kedua. Jakarta: Gunung Agung.

Tilaar, H. A. R. (1998). Manajemen Pendidikan Nasional. Bandung: Remaja Rosda Karya.

Wahab, S. A. (1999). Analisis Kebijaksanaan. Jakarta: Bumi Aksara. 